\title{
Analysis of the Lake Spatio-temporal Change in Naqu of Tibet during Last Thirty Years
}

\author{
Liu Jin-bao,Liu Zhi-hong \\ Chengdu University of Information Technology, \\ Chengdu, China, 610225 \\ liujinbao1107@163.com
}

\author{
Li lin \\ Tibetan Institute of Atmospheric Environment and Science, \\ Lhasa ,China ,850000
}

\begin{abstract}
Nowadays, global change has drawn world attention of scientists and governments. As the unique region unit, The Qinghai-Tibetan Plateau has become the essential area and the hot spot of studying climate change because of its unique nature in the global environmental variation. Glaciers and lakes on the Qinghai-Tibetan Plateau are very sensitive to the climate change as one of the important components in environment. In the last thirty years, climate change over the Qinghai-Tibetan Plateau is obvious. More and more scientists pay attention to its modern climate change and its impact. Taking the topographic map (1:50000) in 1980 as the common base, the series of Landsat MSS, TM/ETM+ images that we used in the research are reprojected to the same coordinate system. Then all data sets are orthorectified based on the DEM data and are accurately co-registered to the topographic map with an accuracy of 1 pixel. All data sets are resampled to $\mathbf{2 8 . 5}$ meters in GRID format. Lakes in Naqu of Tibet are compiled by supervised classifications and on-screen digitizing by manual delineation from the digital images and the topographic map. In ArcGIS, the spatio-temporal integrated data of lake is generated. In this paper, the spatio-temporal variation of lakes in Naqu of Tibet during last thirty years by spatial and temporal integration using Remote Sensing and GIS technologies has been studied. The area of lakes and the quantity of lakes of every county in Naqu of Tibet have been calculated.
\end{abstract}

Keywords- Qinghai-Tibetan Plateau; in Naqu of Tibet; Area of Lake; Quantity of Lake; Remote Sensing; GIS

\section{INTRODUCTION}

The lakes of Qinghai-Tibetan Plateau are affected less by human activities and the changes of lake water quantity are mainly controlled by the climate factors. The trends and processes of the lake area change can well reflect the history of climate change. The survey of lakes on the Qinghai-Tibetan Plateau has been carried out several times and a lot of information has been made by people [1]. Although some scholars have carried out research on the changes of individual lake or the lakes of the typical region in the Qinghai-Tibetan Plateau, the research on the lakes changes is very few in most regions of Qinghai-Tibetan Plateau due to the worse natural environment, the climate characteristic of chillness and oxygen shortage and the poor traffic conditions [2-3]. In recent years, the climate of Qinghai-Tibetan Plateau has a change trend from dry and warm to wet and warm, which accelerates the melting of glaciers and leads to the rise of the lake level. The long-term rising of lake level caused serious harm to the surrounding villages and pasture and forced the residents around the lakes to move upstream. It is particularly necessary for scientists to carry out the research on the correlation between the lake changes and the climate change by which the local government can safeguard the interests of the people and minimize the disaster.

In this study, the lake information in Naqu of Tibet has been extracted by the techniques of artificial visual interpretation using ETM +, TM and MSS data. This paper makes a statistical analysis on the changes of lake area and number. The result that we get from the study not only can provide a wealth of information for future studying on the spatio-temporal change of lakes but also it is significant for us to protect and manage the ecological system scientifically.

\section{OVERVIEW OF STUDY AREA}

Nagqu area is located in the Northern Tibet which is in the hinterland of the Tibet Plateau. Nagqu is the source of major rivers and lakes such as the Yangtze River, the $\mathrm{Nu}$ River, the Lhasa Rive, the Yigong River and so on. It borders on the Xinjiang Uygur Autonomous Region and Qinghai Province.

The terrain of Naqu area is high in the west and low in the east, averaging over 4500 meters above sea level. The Midwestern landscape is flat and there are many hilly basins in this area where inland lakes are scattered like stars in the sky and the rivers are criss-crossed. The east of Naqu belongs to the valley and there are many mountains and valleys in the region which is the only crops sowing areas in Northern Tibet with the altitude from 3500 meters to 4500 meters. There are a small amount of forest resources and shrub grassland in the east of Naqu area where the climate is better than the Midwest. The water resources are abundant in this area where the Yangtze River and $\mathrm{Nu}$ River rise in. The Yangtze River and $\mathrm{Nu}$ River in Naqu area are respectively fed by more than 20 tributaries. The inland lakes and the Brahmaputra are fed by more than 30 tributaries. Furthermore, there are numerous other seasonal rivers and lakes in this area.

\section{DATA ACQUISITION AND PROCESSING}

\section{A. Data Sources}

In this study, the multi-spectral remote sensing data of Landsat are selected as our data source to extract lake 
information. The data include MSS images of 70s with the spatial resolution of 80 meter, the TM images of $90 \mathrm{~s}$, the TM or ETM+ images of 2000 and recent years. The spatial resolution of TM and ETM+ images is 28.5 meters. The topography and administrative maps of Naqu area have been collected as the assistant data.

\section{B. Data Processing}

The process of radiometric correct includes atmospheric correction, radiometric calibration and so on. We can get the apparent reflectance and then extract the remote sensing reflectance from the satellite images by the process of radiometric correct. The process of geometric precision correction generally includes three parts: select the ground control points precisely, select the function of spatial transformation, interpolation re-sampling. The main interpolation methods which are used in the process of geometric correction include three kinds: nearest neighbor, bilinear and cubic convolution [5-6]. In this study, the nearest neighbor method is selected in the process of geometric correction.

\section{RESEARCH METHOD}

Four basic steps are included in this study: collecting and preprocessing the remote sensing images is the first step. The second step is to extract the multi-period lake information of Naqu area according to the spectral characteristics of water [7]. Lakes are compiled by manual delineation from the images and the precision is controlled within 6 pixels. The third step is to make a statistical analysis on the area and number of lake, then the distribution characteristics of lake in Naqu area can be get based on the GIS software. Analyzing the spatiotemporal dynamic changes of lakes in Naqu of Tibet is the forth step [8].

\section{THE SPATIO-TEMPORAL DYNAMIC CHANGES OF LAKES IN NAQU OF TIBE}

\section{A. Analysis on the Change of lake distribution}

The dynamic change will be studied on the lake area and the lake number in Naqu area.

\section{1) Comparison of lake area}

TABLE 1 COMPARISON OF LAKE AREA OF NAQU (UNIT:KM²)

\begin{tabular}{|c|l|l|l|l|}
\hline \multirow{2}{*}{$\begin{array}{c}\text { Lake } \\
\text { Area }\end{array}$} & \multicolumn{4}{|c|}{ Period } \\
\cline { 2 - 5 } & Recent Period & \multicolumn{1}{|c|}{2000} & \multicolumn{1}{c|}{$90 \mathbf{s}$} & \multicolumn{1}{c|}{$70 \mathbf{s}$} \\
\hline Minimum & 0.001164 & 0.000039 & 0.003422 & 0.001655 \\
\hline Maximum & 2288.038819 & 1794.6228 & 1717.042317 & 1643.83788 \\
\hline Sum & 16261.012472 & 13654.790069 & 11952.051658 & 12156.16666 \\
\hline Average & 1.678643 & 2.810206 & 4.168836 & 9.44535 \\
\hline
\end{tabular}

As can be seen from Table 1, the minimum and maximum area of lake of recent years in Naqu area is larger than the lake area of 2000 . From 2000 to recent years, the total area of lake has increased by $2606.222403 \mathrm{~km}^{2}$. The minimum lake area of 90 's in Naqu area is slightly greater than the lake area of 70's, the maximum lake area of 90's is greater than the 70's. From the $70 \mathrm{~s}$ to the $90 \mathrm{~s}$, the total area of lake has decreased by $204.115002 \mathrm{~km}^{2}$. From the $90 \mathrm{~s}$ to the recent years, the total area of lake increased gradually.

\section{2) Comparison of lake number}

TABLE 2 COMPARISON OF LAKE NUMBER OF NAQU

\begin{tabular}{|c|c|c|c|c|}
\hline \multirow{2}{*}{ Lake Area } & \multicolumn{4}{|c|}{ Number } \\
\cline { 2 - 5 } & $\begin{array}{c}\text { Recent } \\
\text { Period }\end{array}$ & 2000 & $\mathbf{9 0 s}$ & $\mathbf{7 0 s}$ \\
\hline$>=0.1 \mathrm{~km}^{2}$ & 1852 & 1531 & 1107 & 1119 \\
\hline$>=0.5 \mathrm{~km}^{2}$ & 645 & 596 & 453 & 568 \\
\hline$>=1 \mathrm{~km}^{2}$ & 434 & 416 & 322 & 390 \\
\hline$>=2 \mathrm{~km}^{2}$ & 307 & 295 & 243 & 261 \\
\hline
\end{tabular}

As can be seen from Table 2, from 2000 to the recent years, the number of lake with the area between $0.1 \mathrm{~km}^{2}$ and $0.5 \mathrm{~km}^{2}$ increased to 1852 from 1531, the number of lake with the area between $0.5 \mathrm{~km}^{2}$ and $1 \mathrm{~km}^{2}$ increased to 645 from 596 , the number of lake with the area between $1 \mathrm{~km}^{2}$ and $2 \mathrm{~km}^{2}$ increased to 451 from 426, the number of lake with the area between $2 \mathrm{~km}^{2}$ and maximum area increased to 307 from 295 . From the $70 \mathrm{~s}$ to the $90 \mathrm{~s}$, the number of lake with the area between $0.1 \mathrm{~km}^{2}$ and $0.5 \mathrm{~km}^{2}$ decreased to 1107 from 1119 , the number of lake with the area between $0.5 \mathrm{~km}^{2}$ and $1 \mathrm{~km}^{2}$ decreased to 453 from 568, the number of lake with the area between $1 \mathrm{~km}^{2}$ and $2 \mathrm{~km}^{2}$ decreased to 322 from 390 , the number of lake with the area between $2 \mathrm{~km}^{2}$ and maximum area decreased to 243 from 261.By comparing the lake number of different periods, it is found that the lakes with smaller area change greatly and the lakes with larger area show a relatively stable state.

In order to better observe the changes of lake during the four periods, the columnar section will be plotted to show the changes of lake number and area.

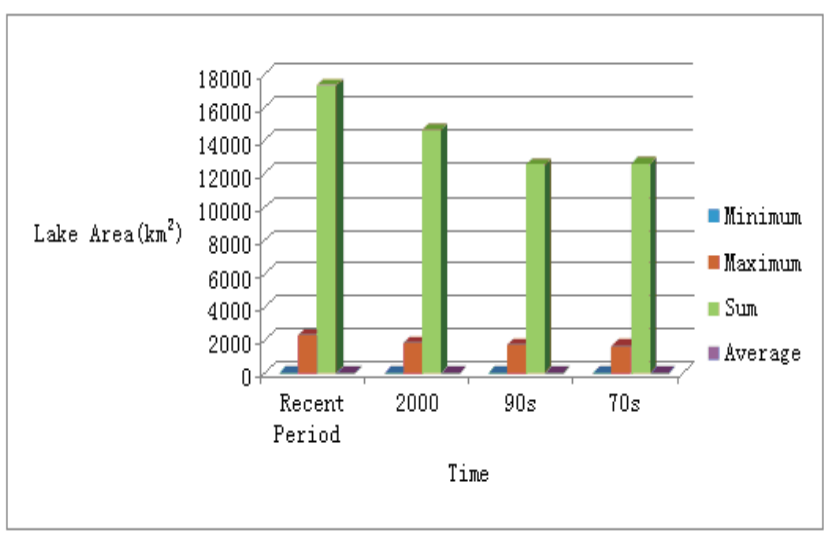

Figure 1. the Comparison of lake area during the four periods 


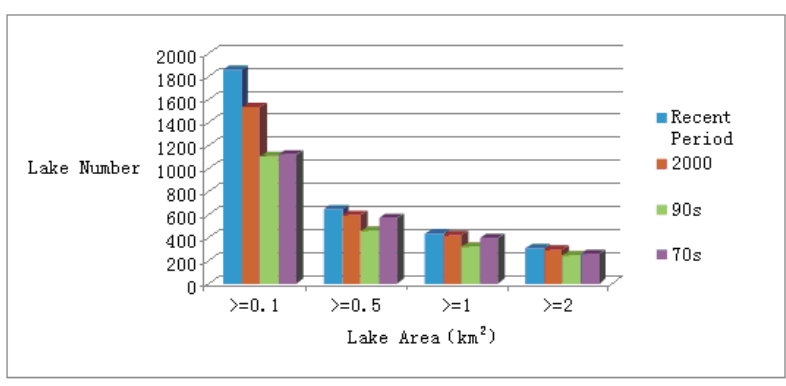

Figure 2. the Comparison of lake number during the four periods

\section{B. the feature analysis of lake distribution in Naqu area}

The dynamic change of every county in Naqu area will be compared and analyzed in the following content.

1) the comparison and analysis of lake area in Naqu area

TABLE 3 THE COMPARISON OF LAKE AREA OF THE RECENT YEARS AND 2000

\begin{tabular}{|c|c|c|c|c|c|c|c|c|}
\hline \multirow{3}{*}{$\begin{array}{l}\text { Country } \\
\text { Name }\end{array}$} & \multicolumn{8}{|c|}{ Lake Ares(Unit:kn') } \\
\hline & \multicolumn{2}{|c|}{ Mrivimum } & \multicolumn{2}{|c|}{ Marimum } & \multicolumn{2}{|c|}{$\operatorname{sim}$} & \multicolumn{2}{|c|}{ Average } \\
\hline & Recent period & 2000 & Recent feriod & 2000 & Recentperiod & 2000 & Recentperiod & 2000 \\
\hline Nyima & 0.002027 & 0.000046 & 845.0149977 & 843.813111 & 3054.105895 & 2743.046937 & 1911205 & 4.319759 \\
\hline Stenrsa & 0.001164 & 0.0059917 & \begin{tabular}{|l|}
877.119534 \\
\end{tabular} & 577.438483 & 2472.288812 & 2186.281384 & 3.185999 & 8887323 \\
\hline Eange & 0.000004 & 0.0000211 & 1103.901949 & 1086.947923 & 3175.3708866 & 2905358191 & 8.944707 & 7.665833 \\
\hline Anduo & 0.00000003 & 0.00000001 & 368.934677 & 291.060892 & 1897.504421 & 1583.657825 & 2.053576 & 2.721062 \\
\hline Nagga & 0.005610 & 0.007513 & 98.579771 & 98.579771 & 304914598 & 275.797749 & 3.587231 & 2.730671 \\
\hline Jaili & 0.006933 & 0.006933 & 6.929849 & 6.945762 & 42.725295 & 43.335446 & 0.418875 & 0.420732 \\
\hline Nierong & 0.011491 & 0.013477 & 2.559983 & 2.030232 & 10.688904 & 10.068397 & 0.154868 & 0.148065 \\
\hline Baqing & 0 & a & 0 & 0 & 0 & 0 & 0 & 0 \\
\hline Suovian & 0 & a & 0 & 0 & 0 & 0 & 0 & 0 \\
\hline Birla & 0.000425 & $\mid 0.011724$ & 5.272828 & 5.341837 & 13.475855 & 13.528617 & 0.299463 & 0.287843 \\
\hline Shruanghn & 0.000035 & 0.000039 & 457.667308 & 386.464484 & 5289.9401034 & 3893.715127 & 0.914582 & 1.41951 \\
\hline
\end{tabular}

TABLE 4 THE COMPARISON OF LAKE AREA OF THE 90'S AND 70's

\begin{tabular}{|c|c|c|c|c|c|c|c|c|}
\hline \multirow{3}{*}{$\begin{array}{l}\text { Country } \\
\text { Name }\end{array}$} & \multicolumn{8}{|c|}{ 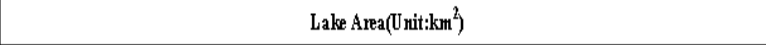 } \\
\hline & \multicolumn{2}{|c|}{ Mivimum } & \multicolumn{2}{|c|}{ Marimum } & \multicolumn{2}{|c|}{$5 \mathrm{sm}$} & \multicolumn{2}{|c|}{ Average } \\
\hline & $90 \mathrm{~s}$ & 7015 & 905 & $70 \mathrm{~s}$ & 20 & $70 \mathrm{~s}$ & 906 & 70.6 \\
\hline Hyima & 0.006487 & 0.001655 & 837.157883 & 839.618299 & 2294.203541 & 2412.755579 & 5882573 & 10.1804003 \\
\hline Sheress & 0.004592 & 0.000314 & 552.166267 & 527.608438 & 2090.243496 & 2072.657567 & 8.894653 & 13635905 \\
\hline Bange & 0.000006 & 0.058906 & 1070.629287 & 1067.703711 & 2805.170196 & 266033696 & 7.343377 & 186007755 \\
\hline Anduo & 0.0000001 & 0.010126 & 274.129127 & 212.960799 & 1483.114485 & 1554.587559 & 2881061 & 9.901832 \\
\hline IV agqu & 0.007513 & 0.117203 & 98.579771 & 97.453865 & 2625980003 & 251.501126 & 2.679571 & 11.976244 \\
\hline Jaili & 0.001835 & 0.110421 & 6952914 & 3778878 & 43568871 & 17.420083 & 0.411027 & 0.757786 \\
\hline Wietong & 0.012102 & 0.058440 & 2.015252 & 2.159972 & 0.652099 & 3.539477 & 0.154378 & 0.398220 \\
\hline Batcing & 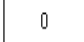 & 96 & 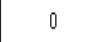 & - & 0 & 3.508966 & 0 & . \\
\hline 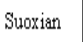 & 0 & & . & & & & 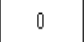 & tos \\
\hline Dinth & & & 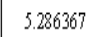 & & 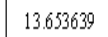 & & 278646 & 2790 \\
\hline uantangun & 0.003422 & 0.005603 & 358.225055 & 373.429844 & 2950.280778 & 3156.055521 & 2754697 & 5833744 \\
\hline
\end{tabular}

As can be seen from Table 3 and Table 4, the lake area of some counties such as Jiali, Nierong, Baqing, Suoxian, Biru shows little change and remains relatively stable, whereas the lake area of other counties such as Nyima, Shenza, Bange, Anduo and Nagqu shows obvious changes. Taking the lake area of Nyima country as an example we can see that the total area of lake decreased to $2294.203541 \mathrm{~km}^{2}$ from 2412.755579 $\mathrm{km}^{2}$ from the $70 \mathrm{~s}$ to the $90 \mathrm{~s}$ and increased to $3054.105895 \mathrm{~km}^{2}$ from $2743.046937 \mathrm{~km}^{2}$ from 2000 to the recent period. The average area of lake in Nyima country decreased to 5.882573 $\mathrm{km}^{2}$ from $10.180403 \mathrm{~km}^{2}$ from the $70 \mathrm{~s}$ to the $90 \mathrm{~s}$ and decreased to $1.911205 \mathrm{~km}^{2}$ from $4.319759 \mathrm{~km}^{2}$ from 2000 to the recent period.

\section{2) The comparison and analysis of lake number in Naqu area}

TABLE 5 THE COMPARISON OF LAKE NUMBER OF THE RECENT YEARS AND 2000

\begin{tabular}{|c|c|c|c|c|c|c|c|c|}
\hline \multirow{3}{*}{$\begin{array}{l}\text { Country } \\
\text { Name }\end{array}$} & \multicolumn{8}{|c|}{ Lake number } \\
\hline & \multicolumn{2}{|c|}{ Total } & \multicolumn{2}{|c|}{$>=0.1 \mathrm{~km}^{2}$} & \multicolumn{2}{|c|}{$>=0 \mathrm{sm}^{2}$} & \multicolumn{2}{|c|}{$>=1 \mathrm{sm}^{2}$} \\
\hline & $\begin{array}{l}\text { Recent } \\
\text { period }\end{array}$ & 2000 & $\begin{array}{l}\text { Recent } \\
\text { period }\end{array}$ & 2000 & $\begin{array}{l}\text { Recent } \\
\text { period }\end{array}$ & 2000 & $\begin{array}{l}\text { Fecent } \\
\text { period }\end{array}$ & 2000 \\
\hline Wyima & 1598 & 635 & 272 & 254 & 126 & 130 & 97 & 98 \\
\hline Sherra & 776 & 246 & 105 & 105 & 50 & 52 & 36 & 37 \\
\hline E ange & 355 & 379 & 168 & 182 & 58 & 55 & 34 & 36 \\
\hline Anduo & 924 & 582 & 230 & 188 & 75 & 64 & 44 & 46 \\
\hline Wagqu & 85 & 101 & 22 & 23 & 11 & 12 & 10 & 10 \\
\hline Jaili & 102 & 103 & 44 & 44 & 18 & 19 & 11 & 11 \\
\hline Wier ong & 69 & 68 & 24 & 23 & 5 & 5 & 1 & 1 \\
\hline Bacing & 0 & a & a & a & a & 0 & a & a \\
\hline Suoxian & 0 & a & a & 0 & 0 & 0 & 0 & 0 \\
\hline Einz & 45 & 47 & 16 & 15 & 5 & 5 & 3 & 3 \\
\hline Shuanghu & 5784 & 2743 & 997 & 719 & 322 & 269 & 220 & 189 \\
\hline
\end{tabular}

TABLE 6 THE COMPARISON OF LAKE NUMBER OF THE 90'S AND 70'S

\begin{tabular}{|c|c|c|c|c|c|c|c|c|}
\hline \multirow{3}{*}{$\begin{array}{l}\text { Country } \\
\text { Name }\end{array}$} & \multicolumn{8}{|c|}{ Lake number } \\
\hline & \multicolumn{2}{|c|}{ Total } & \multicolumn{2}{|c|}{$=0 . \operatorname{lng}^{2}$} & \multicolumn{2}{|c|}{$=0.5 \mathrm{mn}^{2}$} & \multicolumn{2}{|c|}{$>=I \operatorname{lng}^{2}$} \\
\hline & 90 & $70 \mathrm{~s}$ & $90 \mathrm{~s}$ & 705 & 905 & $70 s$ & 905 & 70 \\
\hline Wyim a & 390 & 237 & 189 & 214 & 102 & 143 & 79 & 108 \\
\hline Shenzas & 235 & 152 & 83 & 107 & 45 & 51 & 31 & 32 \\
\hline$B$ ange & 382 & 143 & 171 & 129 & 56 & 56 & 36 & 34 \\
\hline Anduo & 513 & 157 & 171 & 140 & 65 & 66 & 45 & 47 \\
\hline Hazqu & 98 & 21 & 23 & 21 & 11 & 14 & 9 & 10 \\
\hline Jaili & 106 & 23 & 45 & 23 & 19 & 10 & 10 & $s$ \\
\hline Wiet ong & 69 & 34 & 25 & 31 & 5 & 9 & 1 & 2 \\
\hline Bacitig & 0 & 7 & 0 & 6 & 0 & 2 & 0 & 1 \\
\hline Suoxiant & 0 & 1 & 0 & 0 & 0 & 0 & 0 & 1 \\
\hline Binz & 49 & 13 & 16 & 12 & 5 & 6 & 3 & 4 \\
\hline shuanght. & 1071 & 541 & 407 & 469 & 165 & 236 & 124 & 171 \\
\hline
\end{tabular}

From Table 5 and Table 6, we can see clearly the change of total lake number of each county in Nagqu and the change of lake number in different area range. Taking the lake number of Nyima country as an example, we can see that the total number of lake increased to 390 from 237 from the 70 s to the 90 s and increased to 1598 from 635 from 2000 to the recent period. It can be seen that the total number of lakes in Naqu area has a tendency to increase and the number of larger lakes keeps a relatively stable state during the four periods.

\section{Analysis of the Lake Dynamic Changes in Naqu Area}

The dynamic change graph (Figure.3) of lake in Naqu area can be got by the spatial analysis module of ArcMap software which is powerful and useful for our study. It is easy for us to know how the lake changes during the different period by the legend in the graph. The description of the integer in the legend can be seen in Table 7 . 


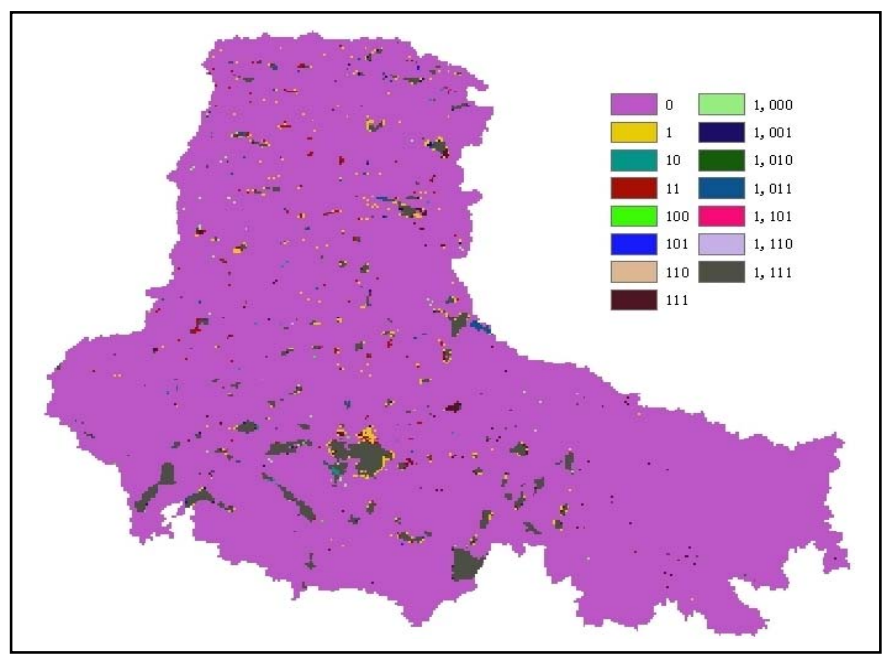

Figure 3. the dynamic change of the lake in Nauq area

Furthermore, we can get the dynamic change graph of lakes of every country in Naqu area. The following Figure 4 shows the dynamic change trend of Shuanghu country.

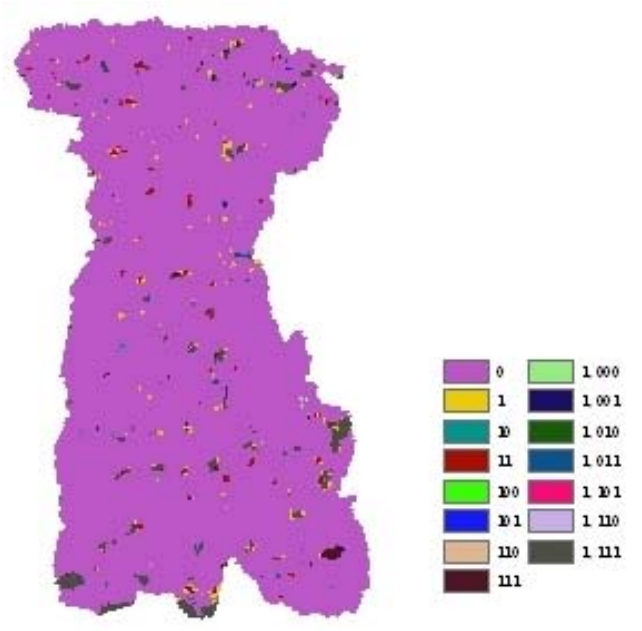

Figure 4. the dynamic change of the lake in Shuanghu country

TABLE7 CODE TABLE FOR DIFFERENT DYNAMIC CHANGE

\begin{tabular}{|l|l|}
\hline \multicolumn{1}{|c|}{ Code } & \multicolumn{1}{c|}{ Meaning } \\
\hline 0 & There are no lakes in all four period \\
\hline 1 & there are lakes only in the recent period \\
\hline 10 & there are lakes only in 2000 \\
\hline 11 & there are lakes only in 2000 and recent period \\
\hline 100 & there are lakes only in the 90s \\
\hline 101 & there are lakes only in the 90s and recent period \\
\hline 110 & there are lakes only in the 90s and 2000 \\
\hline 111 & there are lakes in the 90s, 2000 and recent period \\
\hline 1000 & there are lakes only in the 70s \\
\hline 1001 & there are lakes only in the 70s and recent period \\
\hline 1010 & there are lakes only in the 70s and 2000 \\
\hline 1011 & there are lakes in the 70s 2000 and recent period \\
\hline 1100 & there are lakes only in the 70s and 90s \\
\hline 1101 & there are lakes in the 70s $90 \mathrm{~s}$ and recent period \\
\hline 1110 & there are lakes in the 70s $90 \mathrm{~s}$ and 2000 \\
\hline 1111 & There are lakes in all four period \\
\hline
\end{tabular}

\section{CONCLUSION AND DISCUSSION}

Due to the low precision of the computer automatic classification, we use the artificial visual interpretation to improve the interpretation accuracy in this study. Although the workload is relatively large and the process requires careful, the result that we get is satisfactory. The artificial visual interpretation can not only eliminate the interference of the shadow of the clouds and mountains but also exceeded the limitations of the supervised and unsupervised classification.

According to research result of this paper, we can get the following conclusions:

From the 90s to the recent period, the number and area of lake in Naqu area keep a tendency to increase. The newly increased and expansive lakes mainly distribute in the county of western Nagqu such as Nyima, Shenza, Bangge and Shuanghu. The stable lakes are mostly those lakes with larger area and mainly distribute in the country of eastern Nagqu such as Suoxian. The receding lakes are very less and mainly distribute in the Biru country.

From the 70 s to the 90 s, we find that the area of lakes keeps a tendency to decrease by comparing the data we get. The phenomenon is not normal in the theory. As we know, with the rising of the earth temperature, the glaciers and snow will melt and the total area of lakes should increase gradually. There are reasons as follow: one possible reason is that the images of remote sensing which we used in the study have not good quality and affect the Interpretation accuracy. The other possible reason is that the lakes frozen and can't be interpreted at all.

\section{REFERENCES}

[1] ZHU Da-gang, MENG Xian-gang, ZHENG Da-xing, et al, "Changes of rivers and lakes on the Qinghai-Tibet Plateau in the past 25 years and their influence factors", Geological Bulletin of China, vol. 26, pp.35-39, February 2007

[2] YANG Ri-hong, YU Xue-zheng, LI Yu-long, “ The dynamic analysis of remote sensing information for monitoring the expansion of the selincuo lake in tibet ", Remote Sensing For Land \& Resources ,vol. 56, pp.64 67, June, 2003

[3] WU Yanhong, ZHU Liping, YE Qinghua, WANG Liben, "The Response of Lake-Glacier Area Change to Climate Variations in Namco Basin, Central Tibetan Plateau, during the Last Three Decades ", Acta Geographica Sinica, vol.62, pp.301-311, March,2007

[4] J. C. Hinton, "GIS and remote sensing integration for environmental applications",Geography Information Science,vol.10,pp.877-890, July, 1996

[5] C. C. Petit, E. F. Lambin, “ Integration of multi-source remote sensing data for land cover change detection",Geography Information Science, vol.15,pp.785-803, August,2001

[6] HE Zhi-yong, ZHANG Xiao-can, HUANG Zhi-cai, JIANG Heng-xian, "A water extraction technique based on high-spatial remote sensing images", Journal of Zhejiang University(Sciences Edition), vol. 60, pp.62-65, December,2004

[7] XU Jin-hong,CHEN Shu-juan, “ Extraction of Information About Water Body Based on TM Image”, Research of Soil and Water Conservation, vol.15,pp.161-163, December,2008

[8] LU An-xin, YAO Tan-dong,WANG Li-hong, LIU Shi-yin, GUO Zhilong, " Study on the Fluctuations of Typical Glaciers and Lakes in the Tibetan Plateau Using Remote Sensing”, Journal of Glaciology and Geocryology, vol.15,pp.783-792, December,2005 